\title{
Hydrogen Sulfide: A Rescue Molecule for Mucosal Defence and Repair
}

\author{
John L. Wallace
}

Published online: 17 March 2012

(C) Springer Science+Business Media, LLC 2012

In the past decade, hydrogen sulfide $\left(\mathrm{H}_{2} \mathrm{~S}\right)$ has taken on something of a new identity. Long recognized as an industrial pollutant and environmental toxin, $\mathrm{H}_{2} \mathrm{~S}$ is now known to be produced throughout the body and to regulate important functions in most organs and tissues [1-3]. In the digestive system, $\mathrm{H}_{2} \mathrm{~S}$ exerts potent anti-inflammatory actions, regulates blood flow and smooth muscle tone, modulates epithelial secretion and promotes healing of ulcers $[4,5]$. Indeed, many of the actions of $\mathrm{H}_{2} \mathrm{~S}$ overlap with those of nitric oxide (NO), another gaseous mediator recognized mainly as a pollutant and toxin before its physiological importance was elucidated [1-4].

$\mathrm{H}_{2} \mathrm{~S}$ also bears some similarity to $\mathrm{NO}$ with respect to its synthetic pathways in mammals. Like NO, $\mathrm{H}_{2} \mathrm{~S}$ is synthesized from an amino acid (L-cysteine), and this can occur via three (at least) enzyme pathways. Inhibitors of these pathways are available for use in experimental settings, but they are imperfect, lacking specificity for the target enzymes. A number of $\mathrm{H}_{2} \mathrm{~S}$ donors are available for assessing the effects of this mediator in experimental settings, including some derived from natural products, such as garlic $[3,5]$.

Like $\mathrm{NO}, \mathrm{H}_{2} \mathrm{~S}$ is an important mediator of gastric mucosal defence (Table 1) [5]. Inhibition of endogenous $\mathrm{H}_{2} \mathrm{~S}$ synthesis increases the susceptibility of the mucosa to damage induced by nonsteroidal anti-inflammatory drugs (NSAIDs), for example [6, 7]. On the other hand, exogenous $\mathrm{H}_{2} \mathrm{~S}$ donors can increase the resistance of the mucosa to injury [5-7]. Moreover, $\mathrm{H}_{2} \mathrm{~S}$ synthesis is markedly up-regulated after

\section{J. L. Wallace $(\square)$}

Farncombe Family Digestive Health Research Institute, McMaster University, 1280 Main Street West, HSC-3N4, Hamilton, ON L8S 4K1, Canada

e-mail: jwalla@mcmaster.ca mucosal injury occurs, and it contributes significantly to promoting the healing of the injured tissue $[8,9] \cdot \mathrm{H}_{2} \mathrm{~S}$ donors can accelerate ulcer healing in experimental models $[8,9]$. There is emerging evidence that $\mathrm{H}_{2} \mathrm{~S}$ plays an important role in promoting resolution of inflammation, in part by up-regulating cyclooxygenase-2 expression [9].

In the current issue of this journal, Mard et al. [10] report that administration of $\mathrm{H}_{2} \mathrm{~S}$ just prior to an episode of ischemia-reperfusion can dose-dependently protect the stomach of the rat from damage. Protection could similarly be afforded through administration of L-cysteine, the precursor for $\mathrm{H}_{2} \mathrm{~S}$ synthesis. Further evidence that $\mathrm{H}_{2} \mathrm{~S}$ played a pivotal role in the maintenance of mucosal integrity during ischemia-reperfusion was the observation that suppression of endogenous $\mathrm{H}_{2} \mathrm{~S}$ synthesis, with propargylglycine, resulted in a significant exacerbation of gastric injury.

The authors suggest that it is the suppression of mRNA expression and plasma levels of pro-inflammatory cytokines that accounts for the reduction of gastric damage when the rats were pre-treated with an $\mathrm{H}_{2} \mathrm{~S}$ donor or L-cysteine. One cannot exclude the possibility that the reduced cytokine expression/production occurred, at least in part, as a consequence of the reduced gastric injury, though $\mathrm{H}_{2} \mathrm{~S}$ has been shown to reduce pro-inflammatory cytokine expression/synthesis in other in vivo models, including colitis $[9,11,12]$.

The reduced gastric injury observed in the study of Mard et al. [10] may have been attributable to effects of $\mathrm{H}_{2} \mathrm{~S}$ on any of a number of components of mucosal defence, including bicarbonate secretion [13] and mucosal blood flow [6] (see summary in Table 1). A number of recent studies suggest that the ability of $\mathrm{H}_{2} \mathrm{~S}$ to maintain mitochondrial function in the face of challenges such as ischemia may underlie some of the beneficial effects of this 
Table 1 Mechanisms underlying the gastro-protective effects of hydrogen sulfide

\begin{tabular}{ll}
\hline Effect & Mechanism \\
\hline Maintenance and/or elevation of gastric mucosal blood flow [2,6] & Vasodilation (K+-ATP channels) \\
Stimulation of bicarbonate secretion [13] & Sensory afferent stimulation \\
Reduced pro-inflammatory cytokine expression/release [11, 12] & Inhibition of Nf-KB \\
Increased prostaglandin synthesis [9] & Up-regulation of COX-2 \\
Reduced of leukocyte-endothelial adherence [17] & Reduced adhesion molecule expression \\
Decreased reactive oxygen metabolite production $[18-20]$ & Maintenance of mitochondrial function \\
Enhanced tissue repair [8,21] & Promotion of angiogenesis \\
\hline
\end{tabular}

mediator. This has been elegantly demonstrated by Elrod et al. [14] using an experimental model of myocardial ischemia-reperfusion. $\mathrm{H}_{2} \mathrm{~S}$ was found to reduce myocardial inflammation and to preserve mitochondrial structure and function in this model. Thus, oxidative phosphorylation can be maintained during a period of ischemia, with reduced generation of reactive oxygen species, thereby reducing tissue injury [14]. Over-expression of one of the key enzymes for $\mathrm{H}_{2} \mathrm{~S}$ synthesis (cystathionine- $\beta$ synthase) in cardiac tissue greatly reduced the extent of tissue injury, as did administration of an $\mathrm{H}_{2} \mathrm{~S}$ donor $[14,15]$.

Part of the protective effect of $\mathrm{H}_{2} \mathrm{~S}$ may be related to its ability, like NO [16], to suppress leukocyte adherence to the vascular endothelium [17], a crucial event in the pathogenesis of ischemia-reperfusion injury that contributes to prolonged impairment of tissue perfusion after the ischemic period. The more quickly blood flow can be restored to the mucosa, the less tissue injury will occur. With less post-ischemic leukocyte adherence within postcapillary venules, blood flow is less impaired.

The study of Mard et al. [10] focused on ischemiareperfusion injury in the stomach. $\mathrm{H}_{2} \mathrm{~S}$ is produced and contributes to mucosal defence throughout the GI tract [5]. $\mathrm{H}_{2} \mathrm{~S}$ may also serve as an important energy source in the GI tract, particularly in the colon $[18,19]$. Many species of bacteria within the small and large intestine have the capacity to produce $\mathrm{H}_{2} \mathrm{~S}$, which could potentially influence the mucosa. Enterocytes and colonocytes can very effectively metabolize $\mathrm{H}_{2} \mathrm{~S}$, limiting its penetrance into the subepithelial compartment [18-20]. However, in a setting of epithelial injury or dysfunction, this "metabolic barrier" capacity may be diminished. A significant question that warrants further investigation is: to what extent can bacterially derived $\mathrm{H}_{2} \mathrm{~S}$ influence mucosal structure and function? The development of more selective inhibitors of $\mathrm{H}_{2} \mathrm{~S}$ synthesis and improved methods for measuring $\mathrm{H}_{2} \mathrm{~S}$ synthesis will greatly enhance our ability to address questions such as these.

Conflict of interest Dr. Wallace is a founder of Antibe Therapeutics Ltd., a company focused on hydrogen sulfide-releasing antiinflammatory drugs.

\section{References}

1. Kimura H. Hydrogen sulfide as a neuromodulator. Mol Neurobiol. 2002;26:13-19.

2. Wang R. Two's company, three's a crowd: can $\mathrm{H}_{2} \mathrm{~S}$ be the third endogenous gaseous transmitter? FASEB J. 2002;16:1792-1798.

3. Li L, Rose P, Moore PK. Hydrogen sulfide and cell signaling. Annu Rev Pharmacol Toxicol. 2011;51:169-187.

4. Fiorucci S, Distrutti E, Cirino G, Wallace JL. The emerging roles of hydrogen sulfide in the gastrointestinal tract and liver. Gastroenterology. 2006;131:259-271.

5. Wallace JL. Physiological and pathophysiological roles of hydrogen sulfide in the gastrointestinal tract. Antioxid Redox Signal. 2010;12:1125-1133.

6. Fiorucci S, Antonelli E, Distrutti E, et al. Inhibition of hydrogen sulfide generation contributes to gastric injury caused by antiinflammatory nonsteroidal drugs. Gastroenterology. 2005;129: $1210-1224$.

7. Wallace JL, Caliendo G, Santagada V, Cirino G. Markedly reduced toxicity of a hydrogen sulfide-releasing derivative of naproxen (ATB-346). Br J Pharmacol. 2010;159:1236-1246.

8. Wallace JL, Dicay M, McKnight W, Martin GR. Hydrogen sulfide enhances ulcer healing in rats. FASEB J. 2007;21:4070-4076.

9. Wallace JL, Vong L, McKnight W, et al. Endogenous and exogenous hydrogen sulfide promotes resolution of colitis in rats. Gastroenterology. 2009;137:569-578.

10. Mard SA, Neisi N, Solgi G, Hassanpour M, Darbor M, Maleki M. Gastroprotective effect of NaHS against mucosal lesions induced by ischemia-reperfusion injury in rat. Dig Dis Sci. (Epub ahead of print). doi:10.1007/s10620-012-2051-5.

11. Li L, Rossoni G, Sparatore A, et al. Anti-inflammatory and gastrointestinal effects of a novel diclofenac derivative. Free Radic Biol Med. 2007;42:706-719.

12. Fiorucci S, Orlandi S, Mencarelli A, et al. Enhanced activity of a hydrogen sulphide-releasing derivative of mesalamine (ATB429) in a mouse model of colitis. Br J Pharmacol. 2007;150: 996-1002.

13. Ise F, Takasuka H, Hayashi S, et al. Stimulation of duodenal $\mathrm{HCO}_{3}{ }^{-}$secretion by hydrogen sulphide in rats: relation to prostaglandins, nitric oxide and sensory neurons. Acta Physiol. 2011;201:117-126.

14. Elrod JW, Calvert JW, Morrison J, et al. Hydrogen sulfide attenuates myocardial ischemia-reperfusion injury by preservation of mitochondrial function. Proc Natl Acad Sci USA. 2007;104:15560-15565.

15. Calvert JW, Elston M, Nicholson CK, et al. Genetic and pharmacologic hydrogen sulfide therapy attenuates ischemia-induced heart failure in mice. Circulation. 2010;122:11-19.

16. Wallace JL, McKnight W, Wilson TL, et al. Reduction of shockinduced gastric damage by a nitric oxide-releasing aspirin 
derivative: role of neutrophils. Am J Physiol. 1997;273:G1246G1251.

17. Zanardo RC, Brancaleone V, Distrutti E, et al. Hydrogen sulfide is an endogenous modulator of leukocyte-mediated inflammation. FASEB J. 2006;20:2118-2120.

18. Goubern M, Andriamihaja M, Nübel T, et al. Sulfide, the first inorganic substrate for human cells. FASEB J. 2007;21: $1699-1706$

19. Lagoutte E, Mimoun S, Andriamihaja M, Chaumontet C, Blachier F, Bouillaud F. Oxidation of hydrogen sulfide remains a priority in mammalian cells and causes reverse electron transfer in colonocytes. Biochim Biophys Acta. 2010;1797:1500-1511.

20. Theissen U, Hoffmeister M, Grieshaber M, Martin W. Single eubacterial origin of eukaryotic sulfide:quinoneoxidoreductase, a mitochondrial enzyme conserved from the early evolution of eukaryotes during anoxic and sulfidic times. Mol Biol Evol. 2003;20:1564-1574.

21. Szabó C, Papapetropoulos A. Hydrogen sulphide and angiogenesis: mechanisms and applications. Br J Pharmacol. 2011;164: 853-865. 